\title{
The spread, treatment, and prevention of HIV-1: evolution of a global pandemic
}

\author{
Myron S. Cohen, ${ }^{1}$ Nick Hellmann, ${ }^{2}$ Jay A. Levy, ${ }^{3}$ Kevin DeCock, ${ }^{4}$ and Joep Lange ${ }^{5}$ \\ ${ }^{1}$ University of North Carolina at Chapel Hill, Chapel Hill, North Carolina, USA. ${ }^{2}$ Bill and Melinda Gates Foundation, Seattle, Washington, USA.

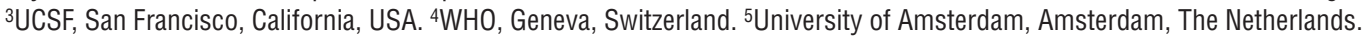

\begin{abstract}
The most up-to-date estimates demonstrate very heterogeneous spread of HIV-1, and more than 30 million people are now living with HIV-1 infection, most of them in sub-Saharan Africa. The efficiency of transmission of HIV-1 depends primarily on the concentration of the virus in the infectious host. Although treatment with antiviral agents has proven a very effective way to improve the health and survival of infected individuals, as we discuss here, the epidemic will continue to grow unless greatly improved prevention strategies can be developed and implemented. No prophylactic vaccine is on the horizon. However, several behavioral and structural strategies have made a difference - male circumcision provides substantial protection from sexually transmitted diseases, including HIV-1, and the application of antiretroviral agents for prevention holds great promise.
\end{abstract}

\section{Introduction}

Now, 28 years after AIDS was first recognized (1), HIV-1 requires continued global focus and investment. The cumulative total of individuals infected with HIV-1 and deaths due to AIDS since the pandemic began exceeds 60 million and 25 million people, respectively (2). At the end of 2007, the Joint United Nations Programme on HIV/AIDS (UNAIDS) and the WHO estimated that there were 33.2 million people living with HIV-1 (see Global estimates of the number of individuals affected by the HIV/AIDS pandemic in 2007), that 2.5 million individuals became newly infected with HIV-1 in 2007, and that 2.1 million people died of AIDS in that year (3). Analysis of the most recent global data confirms the disproportionate impact of HIV/AIDS on sub-Saharan Africa (3) - in 2006, the yearly rate of new infections with HIV-1 (HIV-1 incidence) in the United States was estimated at 40,000-50,000 people (4), whereas in sub-Saharan Africa, it was estimated at 1.7 million (3). The data, however, also showed some encouraging trends, reflecting both the natural evolution of the epidemic as well as the impact of prevention and treatment programs in some settings. For example, global HIV-1 prevalence seems to have been stable since around the end of the 20th century; and HIV-1 incidence peaked worldwide in the late 1990s and has been declining ever since. A reduction in deaths due to AIDS has also occurred globally over the past several years coincident with broader access to antiretroviral therapy (3).

Two broad epidemiologic patterns in the global distribution of HIV-1 infection have emerged. Most countries in the world have concentrated HIV-1 epidemics, in which HIV-1 infection is detected in specific groups at risk, including men who have sex with men (MSM), injecting drug users, sex workers, and the regular partners of such persons (Figure 1). In many countries of sub-Saharan Africa, however, HIV-1 epidemics are generalized, i.e., they are selfsustaining in the population. However, even in settings of generalized epidemics, the risk of infection with HIV-1 is not equal across

Nonstandard abbreviations used: HAART, highly active antiretroviral therapy; HSV-2, herpes simplex virus-2; IRIS, immune reconstitution inflammatory syndrome; LTNP, long-term nonprogressor; MSM, men who have sex with men; PDC, plasmacytoid DC; STD, sexually transmitted disease; TB, tuberculosis.

Conflict of interest: The authors have declared that no conflict of interest exists. Citation for this article: J. Clin. Invest. 118:1244-1254 (2008). doi:10.1172/JCI34706. societies but is increased in persons with higher rates of partner change or who acquire classical sexually transmitted diseases (STDs) and/or in persons who experience other significant potential exposure(s) to HIV-1, such as injection drug use.

Two different types of HIV, HIV-1 and HIV-2, cause infection and disease in humans. HIV-1 is thought to have arisen from cross-species transmission of a chimpanzee virus to humans $(5,6)$ and HIV-2 from cross-species transmission of a Sooty mangabey virus (7). Three groups of HIV-1 have been described, labeled M, N, and O, based on genome differences. Most HIV-1 infections are caused by group $\mathrm{M}$ viruses, and these are divided into 9 subtypes known as clades (A-D, $\mathrm{F}-\mathrm{H}$, J, and $\mathrm{K})$. The DNA sequences of viruses in distinct clades can differ by $15 \%-20 \%$ (8). The most common clade in the Americas, Europe, and Australia is clade B, whereas clade C predominates in the most heavily affected part of the world, southern Africa. Increasingly, recombinant HIV-1 (recombining different clades) are detected: A/G recombinant strains are prevalent in West Africa, and B/C recombinant strains are prevalent in China (8). As will be discussed below, different clades might be transmitted with different levels of efficiency and might differ in their pathogenic potential.

In comparison with HIV-1, HIV-2 is much less prevalent, and individuals infected with HIV-2 are primarily found in West Africa and India and, to a more limited extent, in Portugal and former Portuguese colonies. In addition, infection with HIV-2 is associated with a slower progression to immune deficiency, and the virus seems to be less efficiently transmitted, even from infected women to their offspring (9). Although HIV-2 has no clades, there are 5 groups, of which $A$ and $B$ are the most prominent $(9,10)$. To date, differences between HIV-1 and HIV-2 have not led to major insights that have improved treatment or prevention of infection with HIV-1. Due to space constraints, we restrict our discussion to HIV-1 unless otherwise noted.

In summary, over the past 28 years HIV-1 has moved from a single report of an infection cluster (1) to a worldwide pandemic (3). In this Review, we outline the unequal distribution of the disease across the planet and the biological and behavioral factors that have led to the current situation. We also discuss the molecular pathogenesis of infection, including the unique interaction between the virus and host cells that leads to immunodeficiency and death. Finally, we describe the evolution of HIV-1 treatment 
Global estimates of the number of individuals affected by the HIV/AIDS pandemic in 2007

$\begin{array}{lc} & \text { Number of people living with HIV in } \mathbf{2 0 0 7} \\ \text { Total } & 33.2 \text { million (30.6-36.1 million) } \\ \text { Adults } & 30.8 \text { million (28.2-33.6 million) } \\ \text { Women } & 15.4 \text { million (13.9-16.6 million) } \\ \text { Children }(<15 \mathrm{yr}) & 2.1 \text { million (1.9-2.4 million) } \\ & \text { People newly infected with HIV in } \mathbf{2 0 0 7} \\ \text { Total } & 2.5 \text { million (1.8-4.1 million) } \\ \text { Adults } & 2.1 \text { million }(1.4-4.1 \text { million) } \\ \text { Children }(<15 \mathrm{yr}) & 420,000 \text { (350,000-540,000) } \\ & \text { Deaths due to AIDS in 2007 } \\ \text { Total } & 2.1 \text { million (1.9-2.4 million) } \\ \text { Adults } & 1.7 \text { million (1.6-2.1 million) } \\ \text { Children }(<15 \mathrm{yr}) & 290,000 \text { (270,000-320,000) }\end{array}$

Numbers in parentheses denote estimated ranges. Reproduced with permission from the Joint United Nations Programme on HIV/AIDS (UNAIDS) (http://www.unaids.org; ref. 3).

and prevention, as well as the biomedical advances that have the potential to change the course of the pandemic.

\section{The epidemiology of HIV/AIDS}

Perhaps one of the most surprising aspects of the HIV/AIDS pandemic is the unequal spread of HIV-1. Although no population has been spared (HIV-1 does not respect social status or borders), some regions and populations have been affected far more than others. Unequal spread of HIV-1 reflects a broad combination of biological and social factors.

HIV-1 can be transmitted by contaminated blood and blood products (most importantly by injection drug usage), from an infected mother to her baby (before, during, or after birth and through breast milk), and, most frequently, through either vaginal or anal intercourse. In this section, we depict the geography of HIV-1 by region.

The industrialized world. AIDS was first recognized in the US (1). The US remains the country most heavily affected by the HIV/AIDS pandemic in the industrialized world, and the US epidemic remains a paradigm of HIV/AIDS in the developed world. Currently about three-quarters of newly reported cases of infection with HIV-1 in the US are in men, most of them MSM and especially African American MSM (4). However, there has also been a steady and disturbing increase in the number of women infected with HIV-1 through heterosexual contact (4). Mother-to-child transmission of HIV-1 has been nearly eliminated in the US through routine prenatal screening linked to provision of antiretroviral therapy to those pregnant women who are infected with HIV-1 (11).

In the US, racial and ethnic minorities, especially African Americans and Hispanics, are disproportionately affected by HIV/AIDS, and there is extreme geographic heterogeneity across the country (4). Although the absolute number of cases of infection with HIV-1 are greatest in urban centers, the rural southeastern US is an area of relatively high HIV-1 incidence and prevalence, most probably reflecting a variety of adverse social factors in this region (4).

The HIV-1 epidemic in Western Europe is diverse but was initially fueled by infections among MSM and injecting drug users, the latter especially in the southern part of the continent (3). Italy,
Spain, Portugal, France, and the United Kingdom have been most heavily affected (3). Heterosexual transmission of HIV-1 in Europe has slowly increased, and many infections today are found among immigrants from sub-Saharan Africa (3). In Eastern Europe, where brisk and severe epidemics emerged among injecting drug users in the late 1990s, the most affected countries are the Russian Federation and Ukraine (3).

Low-and middle-income countries. Sub-Saharan Africa now accounts for $68 \%$ of persons living with HIV/AIDS worldwide and for $76 \%$ of all deaths due to AIDS $(2,3)$. In 8 countries in southern Africa, the prevalence of HIV-1 infection in the general population exceeds $15 \%$ (3), and these countries account for almost one-third of the new HIV-1 infections and AIDS deaths in the world. South Africa alone has over 5 million persons infected with HIV-1 (i.e., more than $10 \%$ of the population), more than any other country in the world $(3,12)$.

As of 2007 , approximately $61 \%$ of individuals infected with HIV-1 in Africa were women (3). Almost $90 \%$ of children who are infected with HIV-1 live in Africa (3). Although declines in HIV-1 prevalence have occurred in a number of countries in recent times (most notably in Kenya and Zimbabwe), Africa has witnessed the full devastation of the HIV/AIDS pandemic in a way not seen elsewhere. Important consequences include family disruption, socioeconomic damage, a decrease in life expectancy, a secondary epidemic of tuberculosis (TB), and a dramatic increase in the number of orphans.

The most affected region of the world outside Africa is the Caribbean, where the overall population prevalence of infection with HIV-1 is about $1 \%$, primarily resulting from heterosexual transmission (3). Haiti has been the most heavily affected country, but its HIV-1 prevalence has declined in recent time. HIV/ AIDS in Latin America is diverse in distribution and epidemiology, and approximately one-third of persons in Latin America who are infected with HIV-1 live in Brazil. MSM are the group most affected throughout this region.

In South and Southeast Asia, HIV/AIDS has been concentrated in specific groups at risk, including injecting drug users, female commercial sex workers and their clients, and MSM. In countries with a large population, such as India and the People's Republic of China, concentrated epidemics in specific groups, and low overall prevalence, still convert into large numbers of people infected with HIV-1 (3).

\section{HIV-1 transmission}

Transmission of HIV-1 by whatever route depends on the infectiousness of the "index case" (i.e., the person who transmits the HIV-1 virus) and the susceptibility of the naive host (13). Infectiousness depends on the concentration of HIV-1 and HIV-1infected cells in relevant body fluid (blood or genital tract secretions) (14) as well as virus-specific determinants required for HIV-1 transmission. Biologic strategies for preventing the transmission of HIV-1 to a naive host depend on complete dissection of these rapid and complex biological events.

The concentration of HIV-1 and HIV-1-infected cells in the body. The concentration of HIV-1 in blood and genital secretions varies dramatically depending on the stage of the disease (15). The highest viral loads are detected in the first weeks after infection and in people with advanced disease (Figure 2). The period of acute HIV-1 infection, the first days after infection, can be operationally defined as the window of time following exposure to HIV-1 and the inception of infection and viremia but before HIV-1-specific antibody-mediated immune responses can be reliably detected 

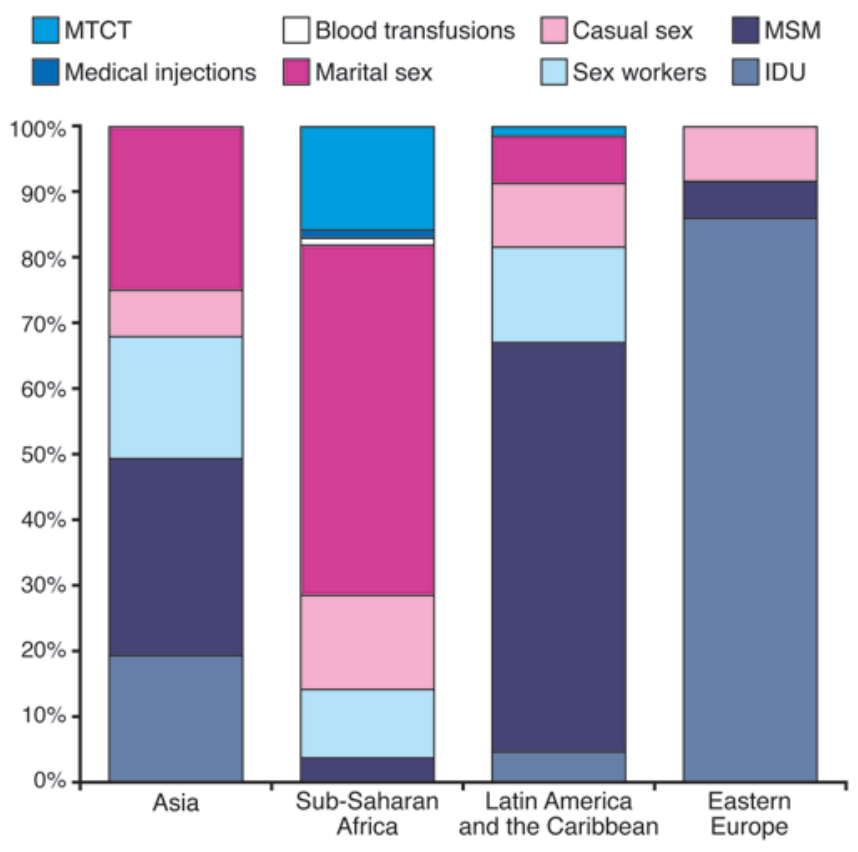

(16). The intense viral replication observed during acute infection (often called ramp-up viremia) is associated with and may be in part caused by a host "cytokine storm" (17). A substantial amount of HIV-1 transmission seems to result from sexual exposure to subjects with acute infection (18). Using empirical data from a study in Uganda (18), Wawer and colleagues reported that HIV-1 transmission during the first 5 months after exposure (which includes acute and early HIV- 1 infection periods) was 0.0081 per coital act, compared to 0.0010 and 0.0043 per coital act in people with established or late HIV-1 infection, respectively. In addition, the magnitude of peak viremia in subjects in sub-Saharan Africa infected with HIV-1 clade C (15) generally exceeds that observed in subjects in the US infected with HIV-1 clade B (19), although the basis for these differences (viral or host factors) is not known. Nevertheless, the high viral loads observed at peak viremia in individuals in sub-Saharan Africa infected with HIV-1 clade C can only serve to further the transmission of the virus.

As acute HIV-1 infection resolves, the viral load reaches a steadystate "set point" that must reflect some combination of virus-specific properties, host genetics, and host defenses (20). Additionally, coinfections with other microbial pathogens seem to affect blood

\section{Figure 2}

HIV-1 viremia and HIV-1 shedding over time. The concentration of HIV-1 in blood and genital secretions varies dramatically depending on the stage of the disease. Shown here are data for HIV-1 viremia and HIV-1 shedding over time in men acutely or chronically infected with HIV-1. Measurements of HIV-1 RNA in blood plasma (gray) and seminal plasma (black) are displayed over 16 weeks. The data were generated from 16 acutely infected subjects, who contributed blood and semen at 60 and 34 time points, respectively, and from 25 chronically infected subjects, who contributed blood and semen at 123 and 89 time points, respectively. The highest viral loads were detected at the first time point after infection and in people with advanced disease. Boxes and whiskers denote the 25th and 75th quartiles and total range of values. Internal circles and horizontal lines represent mean and median, respectively. Reproduced with permission from AIDS (15).

\section{Figure 1}

Source of infections with HIV-1 by region. An individual can become infected with HIV-1 from many sources, including contaminated blood and blood products (such as though medical injections, blood transfusions, and injection drug usage [IDU]), an infected mother transmitting the virus to her baby (before, during, or after birth and through breast milk), and through either vaginal or anal intercourse. The relative importance of a source of HIV-1 varies in different parts of the world. In some countries, infection with HIV-1 is mainly detected in specific groups at risk, including MSM, injecting drug users, sex workers, and the regular partners of such persons. In most countries of sub-Saharan Africa, however, HIV-1 is self-sustaining in the general population through heterosexual intercourse in HIV-serodiscordant couples. MTCT, mother-to-child transmission. The data presented here were mostly generated for 2005 , but some data are from earlier years. Reproduced with permission from the Global HIV Prevention Working Group (103).

and genital tract viral loads (13). For example, modest blood viral load increases have been observed in individuals who are coinfected with the malaria-causing pathogen, which may in turn affect HIV-1 transmission rates and the magnitude of the HIV-1 epidemic in regions where malaria is prevalent (21). Likewise, STDs (both genital ulcers and urethral inflammation) cause reversible increases in cutaneous and genital tract viral concentrations and have consistently been associated with higher prevalence of HIV-1 infection in all geographic regions (13).

Several empirical studies have linked the magnitude of the blood viral burden with HIV-1 transmission $(22,23)$. Modeling exercises suggest that anything that increases viral burden in the genital tract will increase the efficiency of HIV-1 transmission $(13,24)$. Not surprisingly, overwhelming numbers of epidemiologic studies have linked HIV-1 and STDs $(13,25)$, since STDs generally increase the concentration of HIV-1 in the genital tract. In one intervention trial, the treatment of STDs reduced the incidence of HIV-1 (26). Among the STD pathogens, herpes simplex virus-2 (HSV-2) seems to play the most important role because of high worldwide prevalence of infection with the pathogen, recurrent clinical and subclinical HSV-2 reactivation, and concomitant genital ulcers and inflammation (27).

Virus-specific determinants. The viral and cellular requirements for HIV-1 transmission remain incompletely understood. Most recently, Brass et al. (28) applied a unique approach, using siRNA to identify "HIV dependency factors." In this work, the authors confirmed 36 well-recognized factors such as CD4 and CXCR4.

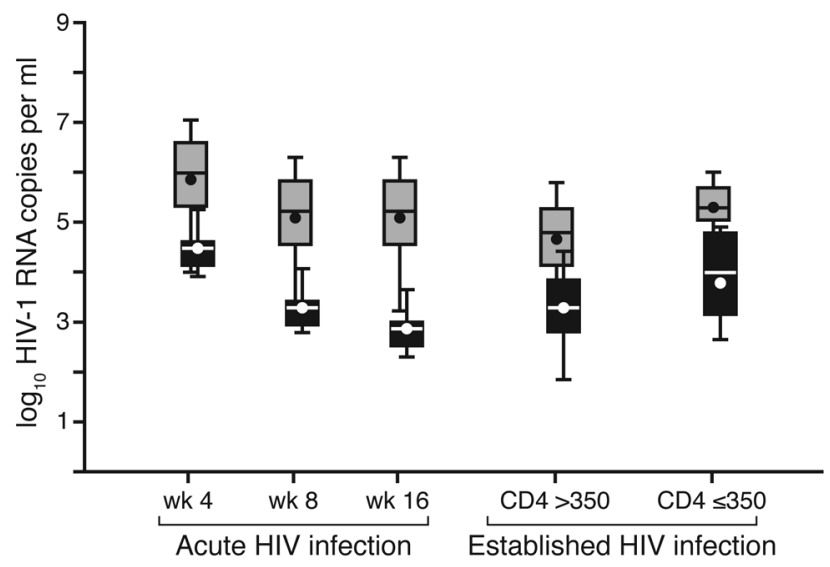


However, they also identified more than 200 novel factors that provide unique insight into the intracellular biology of HIV-1.

More than $80 \%$ of the HIV-1 variants detected in an individual during acute infection come from a single transmitted isolate (M.S. Cohen, unpublished observations). However, some investigators have reported that women show greater viral diversity than men in the early period after transmission (29), perhaps reflecting the large transmission surface area of the cervix and vagina, the complex biological environment of the vagina, and/or the impact of hormonal contraception in some women. HIV-1 isolates can be distinguished by the coreceptor used to infect cells (30). Virions utilizing CCR5 as a coreceptor (R5 viruses) are macrophage-tropic $(30,31)$. Those using CXCR4 (X4 viruses) are T cell-tropic and perhaps more cytopathic. Most of the viruses observed soon after transmission (97\%) utilize CCR5 coreceptors (ref. 31 and M.S. Cohen, unpublished observations), but the reason for this dominance remains unclear. It is possible that one or more characteristic of R5 viruses are required to infect a mucosal cell or for initial replication, although, it is possible that $\mathrm{X} 4$ viruses initiate infection and are then eliminated (32).

Human susceptibility. Human susceptibility to infection with HIV-1 is not uniform. Resistance to infection reflects some combination of genetic factors, innate resistance, and (perhaps very rarely) acquired resistance. Genetic studies have demonstrated that a deletion mutation in the gene encoding CCR5 offers substantial protection from HIV-1 infection (33), and other genetic factors with less powerful impact on acquisition of HIV-1 infection have been reported (34). In the latter case, the gene products that confer resistance to an individual and the way in which this is accomplished are not understood.

Innate resistance might reflect the effects of autochthonous microbial flora and "at-the-ready" immunologic mucosal defenses. For example, women with the change in vaginal flora described as bacterial vaginosis seem to have increased susceptibility to infection with HIV-1 (35). Furthermore, as indicated above, STDs greatly increase the susceptibility of an individual to infection with HIV-1 through erosion of skin or mucosa, local increases in the number of susceptible cells, and increases in the number of receptors for HIV-1 on each cell (13). Conversely, male circumcision offers substantial protection from infection with HIV-1, presumably by removing an easily disrupted entry portal that contains many cellular targets for HIV-1 (36).

Immunity to HIV-1 has been reported in African sex workers who have remained HIV-1 negative despite frequent high-risk behavior $(37,38)$. Such resistance has been associated with a cell-mediated immune response (37) and mucosal antibodies (38). However, no other population-based studies have linked either of these defense mechanisms to protection from infection in humans. In some highrisk uninfected subjects, an innate noncytotoxic HIV-1-specific $\mathrm{CD}^{+} \mathrm{T}$ cell immune response has been correlated with resistance to infection (39). However, HIV-1 superinfection seems to occur fairly frequently (40), suggesting that infection does not induce protection. Finally, although vaccines that evoke a cell-mediated immune response reduce both peak and early viral load in the rhesus macaque model of infection with HIV-1 (41), to date they have failed to prevent infection in animals or humans (see below).

\section{HIV-1 pathogenesis}

After the HIV-1 acquisition event, the interaction between the virus and host determines the natural history of the disease (this varies considerably from person to person) and the probability of a secondary acquisition event(s), which is greatly dependent on the viral load.
To date, the destructive properties of HIV-1 have not been completely unraveled. Yet such understanding is required to prolong host survival and to move toward the ultimate goal of curing this infection.

First, it is useful to compare HIV-1 and HIV-2 (42). Although they are both retroviruses, the pathogenesis of the disease that they cause differs dramatically (9). HIV-1 and HIV-2 have similar genetic structures, but they can differ by up to $40 \%$ at the DNA sequence level (Figure 3) (42). Both viruses have structural and accessory genes that influence replication and pathogenesis (Table 1). Yet infection with HIV-2 is far less pathogenic than is infection with HIV-1 (9).

Differences in biologic properties in the various group M HIV-1 clades have also been observed. Clade D HIV-1 leads to faster disease progression than the other clades, especially clade A (43). Clade C HIV-1 seems to be spreading more rapidly worldwide than other clades (8). Clade C HIV-1 retains the CCR5-tropic phenotype even during disease progression (44), and this characteristic might provide a transmission advantage if the R5 phenotype is favored (see above).

Attachment of HIV-1 to cells expressing CD4 is followed by binding to viral coreceptors and fusion of the cell and the virion, which is mediated through the viral glycoprotein gp41 $(30,31)$. After the interaction at the cell surface, the HIV-1 capsid enters the cell, and this is followed by reverse transcription of viral RNA into double-stranded DNA and then integration of viral DNA into the host genome. The integrated virus can produce virions or remain in a latent (silent) state (45). Latent infection might reflect methylation of the viral genome, reduced Tat or Rev expression, or the activity of cellular proteins such as histone deacetylases (HDACs), PTEFb, and/or a CD8 ${ }^{+}$ T cell antiviral factor(s) (known as CAF) $(45,46)$. Although transmission of HIV-1 generally results from R5 viruses, even when the host is exposed to $\mathrm{X} 4$ and $\mathrm{R} 5$ variants, after several years, $\mathrm{X} 4$ viruses can be detected in at least $50 \%$ of individuals infected with HIV-1, and this shift is strongly associated with more rapid $\mathrm{CD} 4^{+} \mathrm{T}$ cell decline and enhanced progression to $\operatorname{AIDS}(47,48)$. The mechanisms by which $\mathrm{X} 4$ viruses arise is not known, nor is the precise relationship of this viral phenotype to falling $\mathrm{CD} 4^{+} \mathrm{T}$ cell numbers.

$\mathrm{CD}^{+} \mathrm{T}$ cell loss in individuals infected with HIV-1 occurs through direct infection of the $\mathrm{CD}^{+} \mathrm{T}$ cells and through indirect effects resulting from immune activation and apoptosis (49). Loss of gut $\mathrm{CD}^{+} \mathrm{T}$ cells is particularly striking during acute and early HIV-1 infection $(50,51)$. Particular viral proteins and cytokines are toxic to $\mathrm{CD}^{+} \mathrm{T}$ cells, and some $\mathrm{CD}^{+} \mathrm{T}$ cells kill bystander uninfected $\mathrm{CD}^{+} \mathrm{T}$ cells (49). In addition, the virus might inhibit thymic regeneration of $\mathrm{CD}^{+} \mathrm{T}$ cell numbers, thereby limiting recovery of $\mathrm{CD}^{+} \mathrm{T}$ cells in the infected host (49).

Differences in virus replication within various cell types can be influenced by intracellular factors that affect the replicative cycle. Among these is the anti-HIV-1 effect of apolipoprotein B mRNA editing enzyme, catalytic polypeptide-like $3 \mathrm{G}$ (APOBEC3G), a cytidine deaminase that produces an inactive proviral DNA product during reverse transcription (52). The action of this enzyme can be blocked by the viral protein Vif, which targets APOBEC3G for intracellular degradation (52). Another identified intercellular antiviral factor, tripartite motif-containing 5- $\alpha$ (TRIM5- $\alpha$ ), regulates the ability of different viruses to infect human and monkey cells (53). This protein seems to interact with the viral capsid and block uncoating, which is required during an early replicative step (53).

The clinical manifestation of infection with HIV-1 results from the destruction of $\mathrm{CD}^{+} \mathrm{T}$ cells to the point where unusual infectious agents are able to take hold, leading to the "opportunistic" infections that characterize AIDS. However, progression from 

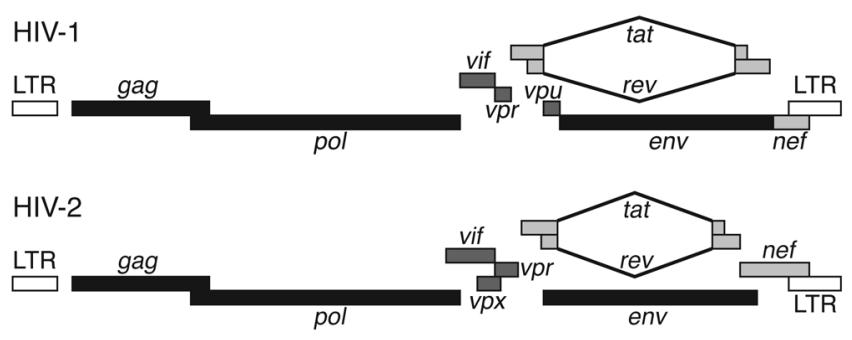

Figure 3

Genomic maps of HIV-1 and HIV-2. Although HIV-1 and 2 have similar genetic structures, the DNA sequences differ by up to $40 \%$. Both viruses have structural and accessory genes that influence replication and pathogenesis (Table 1). Many of these are shared between the two viruses, such as gag and pol; however, only HIV-1 has a gene that encodes Vpu, and Vpx is only encoded by HIV-2. Reproduced from ref. 146.

infection with HIV-1 to AIDS is not inevitable, and some people tolerate infection with the virus for long periods of time without health consequences $(54,55)$. Long-term survivors, also known as long-term nonprogressors (LTNPs), maintain normal CD4 ${ }^{+} \mathrm{T}$ cell counts and low viral load in the absence of antiretroviral therapy $(54,55)$. Such a phenomenon must reflect differences in the HIV-1 variants (e.g., absence of the nef protein; ref. 56), unique host genetic factors (e.g., "protective" HLA polymorphisms; ref. 57), unique host defenses, or all three. Accordingly, it is widely believed that LTNPs can provide clues critical to our understanding of pathogenesis. For example, several genetic factors seem to regulate viral set point (M.S. Cohen, unpublished observations).

Innate and adaptive immunity have central importance in virus control and have both humoral and cellular immune activities. The primary difference between the innate and adaptive immune system is the quick response of innate immunity to an incoming pathogen. The innate immune system recognizes conformational patterns of pathogens rather than specific epitopes (58). Soluble factors involved in innate immune responses include mannosebinding lectins and complement, both of which can inactivate HIV-1 directly (59). Among the cellular immune participants are DCs, NK cells, and a special subset of $\mathrm{CD}^{+} \mathrm{T}$ cells. DCs play a role in both innate and adaptive immunity. Various DC types found throughout the body have the major function of presenting antigen to $\mathrm{T}$ cells and $\mathrm{B}$ cells, resulting in efficient adaptive immune responses (60). The plasmacytoid DCs (PDCs), the dominant producers of type 1 IFNs (60-62), are found in CD4-rich regions of lymphoid tissues and in low numbers in the blood. PDC levels are reduced during infection with HIV-1, particularly in individuals who have progressed to AIDS, but are higher in LTNPs than in healthy controls (63), suggesting that PDCs might play a role in restricting disease progression. PDCs release IFN- $\alpha$ in response to HIV-1 and HIV-1-infected cells (64).
NK cells have an important role in destroying HIV-1-infected cells, and their function depends on efficient production of cytokines such as IL-12 and type 1 IFNs (65). CD8 ${ }^{+} \mathrm{T}$ cells have been identified that also participate in innate responses. They show anti-HIV-1 activity without killing the infected cell. This $\mathrm{CD}^{+} \mathrm{T}$ cell noncytotoxic antiviral response is mediated by a novel, but undefined, $\mathrm{CD}^{+} \mathrm{T}$ cell antiviral factor known as CAF that blocks viral transcription (46). Such responses are highest in LTNPs, and a decrease in these responses leads to HIV-1 replication and disease progression $(54,55)$.

Antibody production is the primary humoral antimicrobial immune response of adaptive immunity and seems to be most important during the early stages of infection with most microbes. Antibodies that can neutralize HIV-1 virions are directed at various regions on the HIV envelope glycoproteins gp120 and gp41, and differences in neutralization sensitivity have been demonstrated among HIV-1 isolates (66). Broadly neutralizing antibodies (i.e., antibodies able to inactivate viruses from various clades and groups) can be identified in the serum of a small number of individuals who are infected with HIV-1 (66), but the relevance of these antibodies is not understood. Genetic and nongenetic factors influence viral sensitivity to neutralization; these include the expression of linear and conformational epitopes, the degree of envelope glycosylation, envelope stability, and whether cellular proteins become attached to the virion surface at the time of budding. Other antibodies that can have a beneficial effect are those that attach to virus-infected cells and induce direct cytotoxic responses of neutrophils and NK cells. Antibody-directed cellular cytotoxicity (ADCC) has been identified in some LTNPs and healthy infected individuals (67). However, some antibodies can bring HIV-1 into T cells and macrophages via the Fc or complement receptor (68) and thereby actually enhance infection; antibodies with these properties have been found in individuals who advance to AIDS (68).

Very early following infection with HIV-1, presentation of antigens by DCs leads to the development of HIV-1-specific CD $4^{+} \mathrm{T}$ cells. These cells can sometimes have cytotoxic activity but primar-

\section{Table 1}

HIV-encoded proteins and their functions

\begin{tabular}{|c|c|}
\hline Protein & Size (kDa) \\
\hline Gag & p24 \\
\hline Gag & p17 \\
\hline Gag & p7 \\
\hline Gag & p6 \\
\hline Polymerase (Pol) & p66, p51 \\
\hline Protease (PR) & p10 \\
\hline Integrase (IN) & p32 \\
\hline Envelope & gp120 \\
\hline Envelope & gp41 \\
\hline Tat $^{A}$ & p14 \\
\hline $\operatorname{Rev}^{A}$ & p19 \\
\hline Nef & p27 \\
\hline Vif & p23 \\
\hline Vpr & p15 \\
\hline Vpu ${ }^{A, B}$ & p16 \\
\hline$V p x^{C}$ & p15 \\
\hline Tev $^{A}$ & p26 \\
\hline
\end{tabular}

ANot found associated within the virion. BOnly present with HIV-1. COnly encoded by HIV-2; may be a duplication of Vpr. Reproduced from ref. 146. 
ily help in the development of HIV-1-specific CD8 ${ }^{+} \mathrm{T}$ cells and $\mathrm{B}$ cells that produce HIV-1-specific antibodies. Activated CD $4^{+} \mathrm{T}$ cells are more susceptible to infection with HIV-1 than other CD $4^{+}$ $\mathrm{T}$ cells in the infected host (69), so destruction of these $\mathrm{CD}^{+} \mathrm{T}$ cells early in infection might cause a lack of immune control of the HIV-1 infection (69).

$\mathrm{CD}^{+} \mathrm{T}$ cell cytotoxic activities are associated with the control of many viral infections (70). This places an emphasis on HIV-1specific CTL responses in preventing infection and advancement to disease (71). Nevertheless, AIDS patients have HIV-1-specific CTLs (72), and some of these CTLs can be detrimental by lysing uninfected "bystander" CD4 ${ }^{+} \mathrm{T}$ cells and DCs (73). Importantly, HIV-1-specific CTLs might not be able to kill virus-infected cells because they lack perforin or other cytotoxic proteins (74). Moreover, HIV-1 has several mechanisms to resist HIV-1-specific CTLs; for example, mutations arise in viral antigenic peptides; DCs express nonimmunogenic viral peptides; and HIV-1-infected APCs exhibit defects in antigen presentation.

\section{Treatment for individuals infected with HIV-1}

The early years of the HIV/AIDS pandemic were characterized by a steep learning curve that connected $\mathrm{CD} 4^{+} \mathrm{T}$ cell numbers (at that time an entirely novel host defense mechanism), viral burden (originally characterized by culture), and characteristic opportunistic infections, reflecting the central importance of $\mathrm{CD}^{+} \mathrm{T}$ cells in the immune response. Improvements in managing opportunistic infections notwithstanding, infection with HIV-1 was usually fatal months or years after the appearance of AIDS-defining symptoms. The recognition that several different classes of agents working at different places in the viral life cycle could inhibit HIV-1 replication remains the most important advance in this field, for both treatment and prevention. The challenge in global health has been in getting the right antiretroviral drugs to the right people at the right time.

Antiretroviral treatment. Antiretroviral drugs are suppressive; they cannot cure infection with HIV-1. However, antiretroviral therapy has changed infection with HIV-1 from an almost uniformly fatal infection into a chronic disease. Indeed, the widespread use of antiretroviral therapy in the US led to rapid and remarkable declines in morbidity and mortality (75). However, shortly after the success of the first agent, azidothymidine (AZT), it became clear that the ability of HIV-1 to generate drug-resistant mutants meant that therapy would require a combination of agents, ultimately referred to as HAART (highly active antiretroviral therapy; ref. 76). HAART combinations are designed to slow the emergence of drug-resistant mutants and permit more durable viral suppression; but they also complicate treatment. In addition, discontinuation of HAART leads to rapid loss of viral suppression (77) as well as other adverse health consequences, including increased risk of opportunistic infections, cardiovascular complications, and death (78).

Despite the success of HAART in the US and Western Europe during the last years of the 20th century, there was initially little push to extend the use of HAART to resource-poor settings where the epidemic was much larger. The 2000 International AIDS Conference in Durban, South Africa, accelerated a breakthrough in worldwide access to HAART. Shortly before the Durban conference, UNAIDS and five major pharmaceutical companies announced an agreement on substantial reductions in the price of the antiretroviral drugs used in HAART combinations for the least-developed nations of the world, especially those in sub-Saharan Africa (the Accelerating Access Initiative). This agreement was followed, in 2001, by a United Nations General Assembly Special Session (UNGASS) on HIV/AIDS that clearly stated that antiretroviral treatment was an essential component of the fight against HIV/AIDS. The WHO subsequently included antiretrovirals on the Essential Medicines List and formulated guidelines for the development of a public health approach to treating individuals in resource-poor settings infected with HIV-1 (79).

More recently, new and substantial funding mechanisms have been established to offer antiretroviral therapy in resource-constrained settings. These include the World Bank's Multi-Country HIV/AIDS Program (MAP), the Global Fund to Fight AIDS, Tuberculosis and Malaria (GFATM), and the US President's Emergency Plan for AIDS Relief (PEPFAR). Through its " 3 by 5 " initiative, the WHO set the ambitious target of having 3 million people in resource-poor settings on HAART by the end of 2005 (80). Although prices of antiretroviral drugs continued to fall, in part because of generic competition, only 1.3 million people were receiving HAART at the end of 2005 and 2.0 million by the end of 2006 (81). Despite not reaching the target of the 3 by 5 initiative, the scale-up in Africa has been very dramatic, rising from 100,000 people receiving HAART at the end of 2003 to 810,000 at the end of 2005 (81) and 1,340,000 (28\% of those in immediate need) at the end of 2006 (81).

Formidable obstacles remain to universal access to antiretroviral therapy (reviewed in ref. 82). In high-prevalence countries, the HIV/AIDS epidemic not only has greatly increased demands on an already understaffed and malfunctioning health sector, but has further compromised the work force because many health care workers are infected with HIV-1. The shortages of doctors and nurses prompt the involvement of less-qualified health care workers and even community members in the delivery of care, so strategies must be clear and simple. Community-based care has been successfully pioneered in diverse, challenging settings, including rural areas and urban slums $(83,84)$ and deserves to be further explored in other regions.

Constraints to antiretroviral treatment in resource-poor settings. The management of HIV/AIDS varies widely by region, depending on financial resources and technology. For example, in high- and middle-income countries, patient information always includes a CD4 ${ }^{+}$ $T$ cell count (reflecting the magnitude of disease progression), the blood plasma viral load (which correlates with the risk and speed of progression), and even viral resistance testing (used to tailor initial therapy and to modify therapy in the event of failure). However, in resource-poor settings, even $\mathrm{CD}^{+} \mathrm{T}$ cell enumeration is not always available, meaning that the decision to initiate antiretroviral therapy is based purely on clinical criteria. Therefore, antiretroviral treatment is often initiated too late in the course of infection to prevent high mortality rates (85). In addition, patients started late on therapy are more likely to suffer an immune reconstitution inflammatory syndrome (IRIS) (86). Although IRIS is incompletely understood, it seems to occur during early restoration of host immune defenses due to HAART in some individuals with chronic opportunistic infections (e.g., tuberculous and non-tuberculous mycobacteria, and fungi) who had been relatively asymptomatic despite low $\mathrm{CD}^{+} \mathrm{T}$ cell numbers and advanced HIV disease.

In resource-constrained countries, the ability to measure plasma HIV-1 RNA load ( $\mathrm{pVL}$ ) to monitor the response of an individual to treatment is even more limited than the ability to enumerate $\mathrm{CD}^{+} \mathrm{T}$ cell numbers. Treatment failure is usually diagnosed late, based on declining numbers of $\mathrm{CD} 4^{+} \mathrm{T}$ cells and/or clinical disease progression. Since these are usually preceded weeks or months ear- 


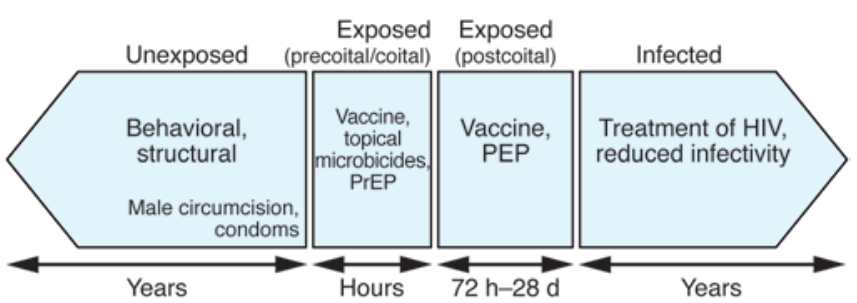

Figure 4

Opportunities for preventing infection with HIV-1. Prevention efforts can be divided into four broad categories: those offered to HIV-1-negative subjects, especially those in high-risk groups (e.g., the offer of male circumcision, condoms); those offered to people with a strong likelihood of recent exposure to HIV-1 (e.g., topical microbicides, antiretroviral preexposure prophylaxis [PrEP]); those offered shortly after exposure (e.g., postexposure prophylaxis [PEP]), and those offered to people who are already infected (secondary prevention; e.g., the use of antiretroviral therapy to reduce viral load).

lier by rising viral burden, extensive viral drug resistance might develop by the time that treatment failure is diagnosed, and transmission of drug-resistant HIV-1 has been observed in Africa (87). There is a great need for the development of affordable and simple $\mathrm{CD}^{+} \mathrm{T}$ cell and viral load assays that can be used at all points of care, including the most rural resource-poor settings (79-82).

Treating individuals infected with HIV-1 and Mycobacterium tuberculosis. The coincidence of infection with HIV-1 and TB in many resourcepoor settings is particularly unfortunate (88). Worldwide, 14 million people are coinfected with HIV-1 and Mycobacterium tuberculosis, and TB has surfaced as the leading cause of death among people infected with HIV-1 in resource-constrained settings (89). Through reduction in host defenses, infection with HIV-1 increases the risk of reactivating latent $M$. tuberculosis (90). Infection with HIV-1 also increases the risk of rapid progression during primary $M$. tuberculosis infection and with subsequent reinfection (91). TB might accelerate the progression to AIDS via immune activation and is associated with a higher mortality and shorter survival in persons who are HIV-1 positive (92). Active TB in those with advanced HIV-1 infection is often atypical and may include extrapulmonary disease. Bacteriological diagnosis can be challenging, since the standard sputum smear test to detect pulmonary TB generally has less than $50 \%$ sensitivity in patients with advanced HIV-1, in part because such patients are less likely to develop pulmonary cavitations (93).

Concomitant treatment of TB and infection with HIV-1 can be difficult. In those with dual infections who begin antiretroviral treatment at advanced stages of HIV-1 infection, there is a high rate of IRIS, leading to considerable early morbidity and mortality
(86). Overlapping drug toxicities (94) and pharmacological interactions between anti-TB drugs and antiretroviral agents narrow antiretroviral treatment choices in those who need concomitant treatment (95). The question of optimal initiation of anti-TB and antiretroviral therapy in coinfected patients remains a research priority. Last, successful global control of TB very much depends on our ability to prevent and treat HIV-1 infections.

Constraints to therapy. The specific antiretroviral therapy choices have been affected by a complex constellation of considerations, and drug rationing has proven necessary, even in the US. Both cost and fear of drug toxicity have limited usage of HAART, but recognition of the advantages of earlier therapy have led to new WHO guidelines suggesting that therapy be initiated when $\mathrm{CD}^{+}$ $\mathrm{T}$ cell numbers fall below 350 cells $/ \mathrm{mm}^{3}$ (81). Cost considerations have also led to the widespread use of a generic fixed-dose HAART combination of d4T/3TC/nevirapine (Triomune; Cipla). Although the short-term tolerance of this combination is generally good, after a few years of treatment, many people develop a disfiguring syndrome, which is referred to as lipodystrophy and is primarily ascribed to d4T (96). In addition, HIV-1 resistance to d4T is rapidly emerging in many countries (87). New WHO treatment guidelines recommend moving away from $\mathrm{d} 4 \mathrm{~T}$-containing HAART regimens (81). However, second-line antiretroviral drug regimens (generally based on drugs that block the viral protease) are even more costly, less available, and more difficult to manage.

Antiretroviral drug choices in pediatric populations are even more limited, even though early therapy in infected neonates is lifesaving; over $50 \%$ of infected infants in low-income countries die during the first two years of life without therapy (97). Children, if treated at all, receive arbitrary dosages of (broken) adult tablets (98), and treatment guidelines and dosing schedules have only recently become available (99).

\section{Prevention of HIV-1 transmission}

Approximately six new individuals became infected with HIV-1 for each person started on HAART in $2006(3,100)$. In the absence of curative therapy, control of the HIV/AIDS epidemic requires broad implementation of effective and sustainable prevention measures. Although successful HAART seems to reduce transmission of HIV-1 (101), other methods to prevent transmission are required, because most individuals infected with HIV-1 are unaware of their status, and few actually receive HAART. Furthermore, since no single intervention has been found to be universally effective at preventing the transmission of HIV-1, packages of specific interventions must be designed for geographic settings according to the local transmission patterns and risk behaviors (Figure 1) (102, 103). Currently, however, less than one in five persons at substan-

\section{Table 2}

Ongoing clinical trials to assess the effectiveness of orally administered antiretroviral drugs in preventing the acquisition of infection with HIV-1

\begin{tabular}{|c|c|c|c|c|c|}
\hline Product & Population enrolled in trial & Number of participants & Site of trial & Trial sponsor & $\begin{array}{l}\text { Year results } \\
\text { expected }\end{array}$ \\
\hline Tenofovir & Male and female injecting drug users & 2,000 & Thailand & $\mathrm{CDC}$ & 2008 \\
\hline Tenofovir & MSM & 400 & US & CDC & 2009 \\
\hline Truvada & Heterosexual men and women & 1,200 & Botswana & CDC & 2010 \\
\hline Truvada & MSM & 3,000 & $\begin{array}{c}\text { South America, US, } \\
\text { South Africa, and Thailand }\end{array}$ & $\mathrm{NIH}$ & 2011 \\
\hline
\end{tabular}


tial risk of infection with HIV-1 in the developing world has access to basic HIV-1 prevention services $(81,82)$.

Prevention efforts can be divided into four broad categories: those offered to HIV-1-negative subjects, especially those in highrisk groups; those offered to people with strong likelihood of exposure to HIV-1 but before such exposure; those offered to people shortly after exposure; and those offered to people who are already infected (secondary prevention) (Figure 4). In addition, effective prevention strategies have been developed to reduce mother-tochild transmission of HIV-1 infection (104) and to reduce blood product transmission of HIV-1 through use of sensitive and reliable screening methods (105).

Behavioral prevention methods. Behavioral interventions were the first prevention methods to be broadly implemented. These interventions have focused on sexual abstinence (106), delayed sexual debut, reduced numbers of sexual partners, routine condom use, and reduced needle sharing or clean needle use among injection drug users (107). However, studies of some single behavioral interventions, such as abstinence-only programs in high-income countries, have failed to show substantial benefit on HIV-1 risk behaviors or biological outcomes (108). Reductions in HIV-1 prevalence in many countries, including the US, Australia, Brazil, Thailand, Uganda, Kenya, and Zimbabwe, have been attributed to combinations of behavioral intervention strategies (108).

Male circumcision. Biological interventions for HIV-1-negative subjects hold considerable promise (109). Three recent randomized, controlled clinical trials have demonstrated the efficacy of adult male circumcision in reducing female-to-male transmission of HIV-1 by approximately 50\%-60\% (110-112). Conversely (and perhaps surprisingly), cervical diaphragms did not offer women significant protection from infection with HIV-1 (113); however, use of diaphragms alone, without concomitant male condom use, was not evaluated. In general, these results offer insight into the acquisition of infection with HIV-1: for men, it seems clear that the foreskin, especially the inner mucosal surface, is a key target for HIV-1 (36); for women, the endocervix is probably not the only site for HIV-1 acquisition (113).

Treating STDs. Although, as discussed above, STDs are welldescribed cofactors in transmission of HIV-1, rendering HIV-1negative subjects more susceptible to infection (13), clinical studies designed to use treatment for an STD to prevent infection with HIV-1 have provided inconsistent results $(25,114-118)$. The differences between these trials have been discussed exhaustively (117), and the results emphasize that to achieve prevention of infection with HIV-1 benefit(s) from the treatment of classical ulcerative and mucosal STDs, it is critical to treat the right people and the right STDs at the right point in time. For example, symptomatic and asymptomatic genital HSV-2 infections are believed to greatly contribute to the spread of HIV-1 $(13,27)$. However, use of HSVsuppressive therapy in HIV-1-negative, HSV-2-positive individuals failed to demonstrate a significant benefit in two large clinical trials $(118,119)$. Another study nearing completion is designed to determine whether chronic suppressive therapy for HSV-2 ulcers in HIV-1/HSV-2 coinfected individuals reduces transmission of HIV-1 to the HIV-1-negative sexual partner (120).

Vaccines. A vaccine that protects individuals from infection with HIV-1 is required to stop the epidemic, and so an absolute worldwide commitment to this goal has been established (121). However, attempts to develop a protective vaccine have been severely compromised by an incomplete understanding of protective HIV-1 immunity and the inability to induce a sufficiently potent immune response against HIV-1 $(122,123)$. To date, two vaccine candidates, a gp120 envelope glycoprotein vaccine (124) and an adenovirus vector vaccine (125), have failed in phase III clinical trials. However, preclinical and early clinical data suggested that these vaccine candidates had limited potential to actually prevent infection. Experiments with rhesus macaques using adenovirus vector vaccines did not actually demonstrate protection from infection with SIV (41). Rather, some infected animals who received adenovirus vector vaccines demonstrated lower peak viral load during acute infection and (transiently) lower viral concentrations at set point (41). However, no similar effects were observed in a human trial with an adenovirus vector vaccine. There was a nonsignificant trend toward greater risk for acquisition of HIV-1 in subjects who had received the vaccine (125), especially in subjects with higher concentrations of antibodies directed to the adenovirus vector. Currently, many investigators believe that an HIV-1 vaccine capable of preventing infection is likely to require the generation of neutralizing or other protective antibodies $(122,123)$, and such a vaccine is unlikely to be available for many years.

Microbicides. Non-vaccine biological interventions designed to prevent infection with HIV-1 after exposure to the virus include topical microbicides. However, multiple first-generation microbicides (nonoxynol-9, cellulose sulphate, and C31G [SAVVY]) have failed to protect in clinical trials (126-129). Indeed, these early microbicides seemed to increase the risk of infection, perhaps through subclinical irritation of the mucosa. Studies to evaluate efficacy of antiretroviral-containing topical microbicides are currently being implemented (109).

Antiviral agents. Perhaps the greatest excitement has been generated by the use of antiretroviral therapy for prevention, as a topical microbicide or as a pre- or postexposure oral prophylaxis to prevent acquisition of HIV-1. The plausibility of this approach is based on the successful use of antiretroviral therapy to prevent mother-to-child transmission (ref. 104 and discussed in detail below) and from a series of animal experiments (130). It has been shown that daily s.c. administration of a combination of the antiviral agents tenofovir and emtricitabine to rhesus macaques provided complete protection from 14 weekly exposures to simian HIV (SHIV), and an oral combination of these agents provided partial protection (130). Conversely, tenofovir alone delayed but did not prevent infection with SHIV in these experiments.

To convert these results from animals to human therapy, clinical trials are underway to assure that HIV-1-negative subjects can safely receive antiretroviral agents and determine whether infection with HIV-1 can be averted in high-risk subjects. A summary of ongoing trials is provided in Table 2 (131). One trial demonstrating the safety of tenofovir in women at high risk of becoming infected with HIV-1 in Africa has been completed, but the study did not have the statistical power to assess efficacy of the regimen for preventing infection with HIV-1 (132). However, trials of antiviral drugs for prevention have proven difficult to complete for scientific, logistical, and political reasons $(133,134)$.

Prevention of mother-to-child transmission during pregnancy, delivery, and breastfeeding (where transmission occurs in 20\%-45\% of cases without an intervention) has been the most successful HIV-1 prevention intervention to date $(11,135,136)$, especially in developed countries, where neonatal infections have been virtually eliminated through routine use of HAART during pregnancy and delivery (135) and where breastfeeding can be safely replaced with infant formula feeding. In addition, use of reliable contraceptives is another effective means to prevent neonatal infections resulting 
from unintended pregnancies in women who are HIV-1-positive (137). Unfortunately, in the developing world, only $11 \%$ of pregnant women are estimated to have access to effective HIV-1 prevention services (99) and reliable contraceptives (137).

Attempts to optimize access to antiviral prophylaxis for vertical (mother-to-child) transmission of HIV-1 emphasize the challenges associated with HIV-1 prevention in resource-poor settings. Singledose nevirapine at delivery has been the most popular agent for peripartum prophylaxis because it is simple to administer and has a well-documented benefit (138). However, single-dose nevirapine does not provide as much protection as more complex regimens. Furthermore, nevirapine resistance has been observed in a substantial number of mothers and babies who have received treatment (139, 140), presumably because the long half-life of the drug gives HIV-1 substantial exposure to a subtherapeutic concentration of the agent and incomplete viral suppression permits selection of drug-resistant HIV-1 variants. Nevirapine resistance that emerges after its use in prophylaxis during pregnancy can compromise the subsequent use of this drug for treatment (141). Strategies are urgently needed to greatly expand access to and maximize the benefits of antiviral prophylaxis for women who are pregnant and neonates (142).

\section{Does antiviral treatment equal prevention?}

As indicated above, HIV-1 transmission events transpire from people with acute, established, and late infection. Infection can result from people who do not know their HIV-1 status and from those who persist in risky sexual behavior despite knowledge of underlying HIV-1 infection. Massive worldwide testing efforts may help those who test positive to better protect their personal health and avoid spreading the infection. Biological, ecological, and observational data (101) suggest that infected subjects who receive HAART are rendered far less contagious (143). On a population level, the lower the viral burden, the less the anticipated spread of HIV-1 (144). However, it is not clear whether the HIV-1 prevention benefits of HAART for an individual or population can be sustained, or whether they can achieve public health relevance (101). Most recently, a Swiss HIV-1 advisory group has generated guidelines to try to help physicians counsel patients about the potential prevention benefits of antiretroviral therapy, a decision that has generated great controversy (145).

1. Centers for Disease Control. 1981. Pneumocystis pneumonia - Los Angeles. MMWR Morb. Mortal. Wkly. Rep. 30:250-252.

2. UNAIDS. 2005. AIDS epidemic update: December 2005. UNAIDS and WHO. Geneva, Switzerland. http://www.unaids.org/epi/2005/doc/EPIupdate2005_pdf_en/epi-update2005_en.pdf.

3. UNAIDS. 2007. AIDS epidemic update: December 2007. http://www.unaids.org/en/KnowledgeCentre/HIVData/EpiUpdate/EpiUpdArchive/2007/ default.asp.

4. Schneider, E., Glynn, M.K., Kajese, T., McKenna, M.T. 2006. Epidemiology HIV/AIDS - United States, 1981-2005. MMWR Morb. Mortal. Wkly. Rep. 55:589-592.

5. Hahn, B.H., Shaw, G.M., De Cock, K.M., and Sharp, P.M. 2000. AIDS as a zoonosis: scientific and public health implications. Science. 287:607-614.

6. Sharp, P.M., Shaw, G.M., and Hahn, B.H. 2005. Simian immunodeficiency virus infection of chimpanzees. J. Virol. 79:3891-3902.

7. Lemey, P., et al. 2003. Tracing the origin and history of the HIV-2 epidemic. Proc. Natl. Acad. Sci. U. S. A. 100:6588-6592.

8. McCutchan, F.E. 2000. Understanding the genetic

\section{Conclusions}

Now, 28 years after HIV/AIDS was first recognized, we have gained remarkable insight into HIV-1 (146). Such information has led to successful treatments that have dramatically reduced HIV-1-related mortality and morbidity and that prevent mother-to-child transmission of HIV-1. We have recognized the critical importance of marrying treatment and prevention efforts $(147,148)$, observed the substantial promise of non-vaccine prevention efforts, and, as emphasized in this report, noted subtle but important differences in the spread and biology of HIV-1 in different parts of the world that might help to explain regional differences in HIV-1 prevalence and survival.

Despite these advances, considerable (and in some cases enormous) problems persist. First, access to and utilization of effective interventions remain limited, especially in the developing world. Second, we have identified no means to cure infection with HIV-1, primarily stymied by our inability to eliminate a "latent pool" of cells in which the HIV-1 genome has integrated into the host genome. Last, we have made only little progress in HIV-1 vaccine development given our incomplete understanding of immunity to HIV-1 infection and induction of potent protective immune responses.

This Review was designed to identify the progress made to date and to underscore the challenges that confront us. An entire generation of clinicians, biological scientists, and social scientists have devoted their lives to understanding the biology of HIV transmission and pathogenesis and to developing ways to interrupt the pandemic. The groundwork laid by these individuals sets the stage for the next generation of investigators, who have no choice but to move forward with the greatest urgency.

\section{Acknowledgments}

The authors wish to thank Lisa Chensvold and Christopher Hurt (both at the University of North Carolina at Chapel Hill) for their assistance in preparation of this manuscript and Angela Kashuba for assistance in preparation of Figure 4.

Address correspondence to: Myron S. Cohen, University of North Carolina at Chapel Hill, 130 Mason Farm Road, Room 2115, Campus Box 7030, Chapel Hill, North Carolina 27514, USA. Phone: (919) 966-2536; Fax: (919) 966-6714; E-mail: mscohen@med.unc.edu. diversity of HIV-1. AIDS. 14(Suppl. 3):S31-S44

9. Jaffar, S., Grant, A.D., Whitworth, J., Smith, P.G., and Whittle, H. 2004. The natural history of HIV-1 and HIV-2 infections in adults in Africa: a literature review [erratum 2004, 82:571]. Bull. World Health Organ. 82:462-469.

10. Damond, F., et al. 2004. Identification of a highly divergent HIV type 2 and proposal for a change in HIV type 2 classification. AIDS Res. Hum. Retroviruses. 20:666-672.

11. Mofenson, L., et al. 2006. Achievements in public health. Reduction in perinatal transmission of HIV infection - United States, 1985-2005. MMWR Morb. Mortal. Wkly. Rep. 55:592-597.

12. UNAIDS/World Health Organization. 2006. UNAIDS/WHO epidemiological fact sheets on HIV/AIDS and sexually transmitted diseases, 2006 update. WHO. Geneva, Switzerland. http://www. who.int/hiv/pub/epidemiology/pubfacts/en/.

13. Galvin, S.R., and Cohen, M.S. 2004. Sexual transmission of HIV. Nat. Rev. Microbiol. 2:33-42.

14. Levy, J.A. 1988. The transmission of AIDS: the case of the infected cell. JAMA. 259:3037-3038.

15. Pilcher, C.D., et al. 2007. Amplified transmission of HIV-1: comparison of HIV-1 concentrations in blood and semen in acute and chronic infection. AIDS. 21:1723-1730.

16. Pilcher, C.D., Eron, J.J., Jr., Galvin, S., Gay, C., and Cohen, M.S. 2004. Acute HIV revisited: new opportunities for treatment and prevention. J. Clin. Invest. 113:937-945.

17. Stacey, A., et al. 2007. Elevations in plasma levels of innate cytokines prior to the peak in plasma viremia in acute HIV-1 infection [abstract]. The Keystone Symposia Global Health Series. HIV vaccines: from basic research to clinical trials (X7). March 25-30. Whistler, British Columbia, Canada.

18. Wawer, M.J., et al. 2005. HIV-1 transmission per coital act, by stage of HIV-1 infection, in Rakai, Uganda. J. Infect. Dis. 191:1403-1409.

19. Pilcher, C.D., et al. 2004. brief but efficient: acute HIV infection and the sexual transmission of HIV. J. Infect. Dis. 189:1785-1792.

20. Fellay, J., et al. 2007. A whole-genome association study of major determinants for host control of HIV-1. Science. 317:944-947.

21. Abu-Raddad, L.J., Patnaik, P., and Kublin, J.G. 2006. Dual infection with HIV and malaria fuels the spread of both diseases in sub-Saharan Africa [erratum 2007, 315:598]. Science. 314:1603-1606. 
22. Quinn, T.C., et al. 2000. Viral load and heterosexual transmission of human immunodeficiency virus type 1. Rakai Project Study Group. N. Engl. J. Med. 342:921-929.

23. Fideli, U.S., et al. 2001. Virologic and immunologic determinants of heterosexual transmission of human immunodeficiency virus type 1 in Africa. AIDS Res. Hum. Retroviruses. 17:901-910.

24. Chakraborty, H., et al. 2001. Viral burden in genital secretions determines male-to-female sexual transmission of HIV-1: a probabilistic empiric model. AIDS. 15:621-627.

25. Fleming, D.T., and Wasserheit, J.N. 1999. From epidemiological synergy to public health policy and practice: the contribution of other sexually transmitted diseases to sexual transmission of HIV infection. Sex. Transm. Infect. 75:3-17.

26. Grosskurth, H., et al. 1995. Impact of improved treatment of sexually transmitted diseases on HIV infection in rural Tanzania: randomized controlled trial. Lancet. 346:530-536.

27. Freeman, E.E., et al. 2006. Herpes simplex virus 2 infection increases HIV acquisition in men and women: systematic review and meta-analysis of longitudinal studies. AIDS. 20:73-83.

28. Brass, A.L., et al. 2008. Identification of host proteins required for HIV infection through a functional genomic screen. Science. 319:921-926.

29. Long, E.M., et al. 2000. Gender differences in HIV-1 diversity at time of infection. Nat. Med. 6:71-75

30. Levy, J.A. 1996. Infection by human immunodeficiency virus - CD4 is not enough. N. Engl. J. Med. 335:1528-1530.

31. Berger, E.A., Murphy, P.M., and Farber, J.M., 1999. Chemokine receptors as HIV-1 coreceptors: roles in viral entry, tropism, and disease. Annu. Rev. Immunol. 17:657-700.

32. Moore, J.P., Kitchen, S.G., Pugach, P., and Zack, J.A 2004. The CCR5 and CXCR4 coreceptors - central to understanding the transmission and pathogenesis of human immunodeficiency virus type 1 infection. AIDS Res. Hum. Retroviruses. 20:111-126.

33. Liu, R., et al. 1996. Homozygous defect in HIV-1 coreceptor accounts for resistance of some multiply-exposed individuals to HIV-1 infection. Cell. 86:367-377

34. Gonzalez, E., et al. 2005. The influence of CCL3L1 gene-containing segmental duplications on HIV1/AIDS susceptibility. Science. 307:1434-1440.

35. Taha, T.E., et al. 1998. Bacterial vaginosis and disturbances of vaginal flora: association with increased acquisition of HIV. AIDS. 12:1699-1706.

36. Donoval, B.A., et al. 2006. HIV-1 target cells in foreskins of African men with varying histories of sexually transmitted infections. Am. J. Clin. Pathol. 125:386-391

37. Rowland-Jones, S.L., et al. 1998. Cytotoxic T cell responses to multiple conserved HIV epitopes in HIV-resistant prostitutes in Nairobi. J. Clin. Invest. 102:1758-1765.

38. Kaul, R., et al. 1999. HIV-1-specific mucosal IgA in a cohort of HIV-1-resistant Kenyan sex workers. AIDS. 13:23-29.

39. Stranford, S., et al. 1999. Lack of infection in HIVexposed individuals is associated with a strong CD8+ cell noncytotoxic anti-HIV response. Proc. Natl. Acad. Sci. U. S. A. 96:1030-1035.

40. Piantadosi, A., Chohan, B., Chohan, V., McClelland, R.S., and Overbaugh, J. 2007. Chronic HIV-1 infection frequently fails to protect against superinfection. PLoS Pathog. 3:e177.

41. Letvin, N.L., et al. 2006. Preserved CD4+ central memory T cells and survival in vaccinated SIV-challenged monkeys. Science. 312:1530-1533.

42. Robertson, D.L., et al. 2000. HIV-1 nomenclature proposal. Science. 288:55-56.

43. Baeten, J.M., et al. 2007. HIV-1 subtype D infection is associated with faster disease progression than subtype A in spite of similar plasma HIV-1 loads. J. Infect. Dis. 195:1177-1180.

44. Ping, L.H., et al. 1999. Characterization of V3 sequence heterogeneity in subtype $\mathrm{C}$ human immunodeficiency virus type 1 isolates from Malawi: underrepresentation of X4 variants. J. Virol. 73:6271-6281.

45. Siliciano, J.D., and Siliciano, R.F. 2000. Latency and viral persistence in HIV-1 infection. J. Clin. Invest. 106:823-825.

46. Levy, J.A. 2003. The search for the CD8+ cell antiHIV factor (CAF). Trends in Immunol. 24:628-632.

47. Cheng-Mayer, C., Seto, D., Tateno, M. and Levy, J.A. 1988. Biologic features of HIV that correlate with virulence in the host. Science. 240:80-82.

48. Connor, R.I., Sheridan, K.E., Ceradini, D., Choe, S., and Landau, N.R. 1997. Change in coreceptor use correlates with disease progression in HIV-1infected individuals. J. Exp. Med. 185:621-628.

49. McCune, J.M. 2001. The dynamics of CD4+ T-cell depletion in HIV disease. Nature. 410:974-979.

50. Mehandru, S., et al. 2004. Primary HIV-1 infection is associated with preferential depletion of CD4+ T lymphocytes from effector sites in the gastrointestinal tract. J. Exp. Med. 200:761-770.

51. Brenchley, J.M., et al. 2004. CD4+ T cell depletion during all stages of HIV disease occurs predominantly in the gastrointestinal tract. J. Exp. Med. 200:749-759.

52. Sheehy, A.M., Gaddis, N.C., Chol, J.D., and Malim, M.H. 2002. Isolation of a human gene that inhibits HIV-1 infection and is suppressed by the viral Vif protein. Nature. 418:646-650

53. Stremlau, M., et al. 2004. The cytoplasmic body component TRIM5a restricts HIV-1 infection in Old World monkeys. Nature. 427:848-853.

54. Cao, Y., Qin, L., Zhang, L., Safrit, J., and Ho, D.D. 1995. Virologic and immunologic characterization of long-term survivors of human immunodeficiency virus type 1 infection N. Engl. J. Med. 332:201-208

55. Pantaleo, G., et al. 1995. Studies in subjects with long-term nonprogressive human immunodeficiency virus infection. N. Engl. J. Med. 332:209-216.

56. Deacon, N.J., et al. 1995. Genomic structure of an attenuated quasi species of HIV-1 from a blood transfusion donor and recipients. Science. 270:988-991

57. Bansal, A., et al. 2007. Immunological control of chronic HIV-1 infection: HLA-mediated immune function and viral evolution in adolescents. AIDS. 21:2387-2397.

58. Akira, S., Uematsu, S., and Takeuchi, O. 2006. Pathogen recognition and innate immunity. Cell. 124:783-801.

59. Spear, G.T. 1993. Interaction of non-antibody factors with HIV in plasma. AIDS. 7:1149-1157.

60. Piguet, V., and Steinman, R.M. 2007. The interaction of HIV with dendritic cells: outcomes and pathways. Trends Immunol. 28:503-510.

61. Siegal, F.P., et al. 1999. The nature of the principal type 1 interferon-producing cells in human blood. Science. 284:1835-1837.

62. Ito, T., Kanzler, H., Duramad, O., Cao, W., and Liu, Y.J. 2006. Specialization, kinetics, and repertoire of type 1 interferon responses by human plasmacytoid predendritic cells. Blood. 107:2423-2431.

63. Soumelis, V., Scott, I., Gheyas, F., Bouhour, D. Cozon, G., 2001. Depletion of circulating natural type 1 interferon-producing cells in HIV-infected AIDS patients. Blood. 98:906-912.

64. Schmidt, B., Ashlock, B.M., Foster, H., Fujimura, S., and Levy, J.A. 2005. HIV-infected cells are major inducers of plasmacytoid dendritic cells (PDC) interferon production, maturation and migration. Virology. 343:256-266.

65. Cooper, M.A., Fehniger, T.A., and Caligiuri, M.A. 2001. The biology of human natural killer-cell sub- sets. Trends Immunol. 22:633-640.

66. Burton, D.R., et al. 2004. HIV vaccine design and the neutralizing antibody protection. Nat. Immunol. 5:233-236.

67. Forthal, D.N., Gilbert, P.B., Landucci, G., and Phan, T. 2007. Recombinant gp120 vaccine-induced antibodies inhibit clinical strains of HIV-1 in the presence of Fc receptor-bearing effector cells and correlate inversely with HIV infection rate. J. Immunol. 178:6596-6603.

68. Homsy, J., Meyer, M., and Levy, J.A. 1990. Serum enhancement of human immunodeficiency virus (HIV) correlates with disease in HIV infected individuals. J. Virol. 64:1437-1440.

69. Douek, D.C., et al. 2002. HIV preferentially infects HIV-specific CD4+ T cells. Nature. 417:95-98.

70. Kagi, S., et al. 1995. The role of perforin- and Fasdependent cytotoxicity in protection against cytopathic and noncytopathic viruses. Eur. J. Immunol. 25:3256-3262.

71. Ogg, G.S., et al. 1998. Quantitation of HIV-1-specific cytotoxic $\mathrm{T}$ lymphocytes and plasma load of viral RNA. Science. 279:2103-2106.

72. Haas, G., et al. 1996. Dynamics of viral variants in HIV-1 Nef and specific cytotoxic T lymphocytes in vivo. J. Immunol. 157:4212-4221.

73. Zinkernagel, R.M., and Hengartner, H. 1994. T-cellmediated immunopathology versus direct cytolysis by virus: implications for HIV and AIDS. Immunol. Today. 15:262-268.

74. Lieberman, J. 2004. Tracking the killers: how should we measure CD8 T cells in HIV infection? AIDS. 18:1489-1493.

75. Palella, F.J., Jr., et al. 1998. Declining morbidity and mortality among patients with advanced human immunodeficiency virus infection. HIV Outpatient Study Investigators. N. Engl. J. Med. 338:853-860.

76. Larder, B. 2001. Mechanisms of HIV-1 drug resistance. AIDS. 15(Suppl. 5):S27-S34

77. Kaufmann, D.E., et al. 2004. Limited durability of viral control following treated acute HIV infection. PLoS Med. 1:e36.

78. Strategies for Management of Antiretroviral Therapy (SMART) Study Group, et al. 2006. CD4+ countguided interruption of antiretroviral treatment. N. Engl. J. Med. 355:2283-2296.

79. [Anonymous]. 2002. Scaling up antiretroviral therapy in resource-limited settings: guidelines for a public health approach. WHO. Geneva, Switzerland. http://www.who.int/entity/hiv/pub/prev_ care/en/arvrevision2003en.pdf.

80. [Anonymous]. 2003. Treating 3 million by 2005: making it happen. WHO. Geneva, Switzerland. ttp://www.who.int/entity/3by5/publications/documents/en/3by5StrategyMakingItHappen.pdf.

81. [Anonymous]. 2006. Antiretroviral therapy for HIV infection in adults and adolescents: recommendations for a public health approach. WHO. Geneva, Switzerland. http://www.who.int/hiv/pub/guidelines/adult/en/index.html.

82. Ojikutu, B. 2007. Introduction: the realities of antiretroviral therapy rollout: overcoming challenges to successful programmatic implementation. J. Infect. Dis. 196(Suppl. 3):S445-S448.

83. Farmer, P., et al. 2001. Community-based approaches to HIV treatment in resource-poor settings. Lancet. 358:404-409.

84. Marston, B.J., et al. 2007. A program to provide antiretroviral therapy to residents of an urban slum in Nairobi, Kenya. J. Int. Assoc. Physicians AIDS Care (Chic. Ill.). 6:106-112.

85. Braitstein, P., et al. 2006. Mortality of HIV-1infected patients in the first year of antiretroviral therapy: comparison between low-income and high-income countries. Lancet. 367:817-824.

86. French, M.A., Price, P., and Stone, S.F. 2004. Immune restoration disease after antiretroviral therapy. AIDS. 18:1615-1627. 
87. Ferradini, L., et al. 2006. Scaling up of highly active antiretroviral therapy in a rural district of Malawi: an effectiveness assessment Lancet. 367:1335-1342.

88. Corbett, E.L., Marston, B., Churchyard, G.J., and De Cock, K.M. 2006. Tuberculosis in sub-Saharan Africa: opportunities, challenges, and change in the era of antiretroviral therapy. Lancet. 367:926-937.

89. The Stop TB Partnership. TB/HIV - facts at a glance. http://www.stoptb.org/news/archives/ iacxv/assets/InfoPack/InfoPackEnglish.pdf.

90. Bucher, H.C., et al. 1999. Isoniazid prophylaxis for tuberculosis in HIV infection: a meta-analysis of randomized controlled trials. AIDS. 13:501-507.

91. Daley, C.L., et al. 1992. An outbreak of tuberculosis with accelerated progression among persons infected with the human immunodeficiency virus: an analysis using restriction-fragment length polymorphisms. N. Engl. J. Med. 326:231-235.

92. Whalen, C.C., et al. 2000. Impact of pulmonary tuberculosis on survival of HIV-infected adults: a prospective epidemiologic study in Uganda. AIDS. 14:1219-1228

93. Jones, B.E., et al. 1993. Relationship of the manifestations of tuberculosis to CD4 cell counts in patients with human immunodeficiency virus infection. Am. Rev. Respir. Dis. 148:1292-1297.

94. Lee, W.M. 2003. Drug-induced hepatotoxicity. N. Engl. J. Med. 349:474-485

95. De Maat, M.M., et al. 2003. Drug interactions between antiretroviral drugs and co-medicated agents. Clin. Pharmacokinet. 42:223-282.

96. van der Valk, M., et al. 2004. Prevalence of lipoatrophy and mitochondrial DNA content of blood and subcutaneous fat in HIV-1-infected patients randomly allocated to zidovudine- or stavudinebased therapy. Antivir. Ther. 9:385-393.

97. Newell, M.L., et al. 2004. Mortality of infected and uninfected infants born to HIV-infected mothers in Africa: a pooled analysis. Lancet. 364:1236-1243.

98. Puthanakit, T., et al. 2005. Efficacy of highly active antiretroviral therapy in HIV-infected children participating in Thailand's national access to antiretroviral program. Clin. Infect. Dis. 41:100-107.

99. [Anonymous]. 2007. Antiretroviral therapy for HIV infection in infants and children: towards universa access. WHO. Geneva, Switzerland. http://www. who.int/hiv/pub/guidelines/paediatric020907.pdf

100. [Anonymous]. 2007. Towards universal access: scaling up priority HIV/AIDS interventions in the health sector. Progress report. WHO. Geneva, Switzerland. http://www.who.int/hiv/mediacentre/universal_ access_progress_report_en.pdf.

101.Cohen, M.S., Gay, C., Kashuba, A.D., Blower, S., and Paxton, L. 2007. Narrative review: antiretroviral therapy to prevent the sexual transmission of HIV-1. Ann. Intern. Med. 146:591-601.

102.Wegbreit, J., Bertozzi, S., DeMaria, L.M., and Padian, N.S. 2006. Effectiveness of HIV prevention strategies in resource-poor countries: tailoring the intervention to the context. AIDS. 20:1217-1235

103.Global HIV Prevention Working Group. 2007. Bringing HIV prevention to scale: an urgent global priority. http://www.globalhivprevention.org/ index.html.

104.Dao, H., et al. 2007. International recommendations on antiretroviral drugs for treatment of HIVinfected women and prevention of mother-to-child HIV transmission in resource-limited settings:2006 update. Am. J. Obstet. Gynecol. 197:S42-S55.

105. Stramer, S.L., et al. 2004. Detection of HIV-1 and HCV infections among antibody-negative blood donors by nucleic acid-amplification testing. N. Engl. J. Med. 351:760-768.

106.Underhill, K., Montgomery, P., and Operario, D. 2007. Sexual abstinence only programs to prevent HIV infection in high income countries: systematic review. BMJ. 335:248-259.
107.Des Jarlais, D.C., and Friedman, S.R. 1987. HIV infection among intravenous drug users: epidemiology and risk reduction. AIDS. 1:67-76.

108.Stoneburner, R.L., and Low-Beer, D. 2004. Population-level HIV declines and behavioral risk avoidance in Uganda. Science. 304:714-718.

109. Cohen, M.S. 2007. Preventing sexual transmission of HIV. Clin. Infect. Dis. 45(Suppl. 4):S287-S292.

110.Auvert, B., et al. 2005. Randomized, controlled intervention trial of male circumcision for reduction of HIV infection risk: the ANRS 1265 Trial. PLoS Med. 2:e298.

111.Gray, R.H., et al. 2007. Male circumcision for HIV prevention in men in Rakai, Uganda: a randomised trial. Lancet. 369:657-666.

112. Bailey, R.C., et al. 2007. Male circumcision for HIV prevention in young men in Kisumu, Kenya: a randomised controlled trial. Lancet. 369:643-656.

113.Padian, N.S., et al. 2007. Diaphragm and lubricant gel for prevention of HIV acquisition in southern African women: a randomised controlled trial. Lancet. 370:251-261

114.Grosskurth, H., et al. 1995. Impact of improved treatment of sexually transmitted diseases on HIV infection in rural Tanzania: randomised controlled trial. Lancet. 346:530-536.

115. Kamali, A., et al. 2003. Syndromic management of sexually-transmitted infections and behaviour change interventions on transmission of HIV-1 in rural Uganda: a community randomised trial. Lancet. 361:645-652.

116. Wawer, M.J., et al. 1999. Control of sexually transmitted diseases for AIDS prevention in Uganda: a randomised community trial. Rakai Project Study Group. Lancet. 353:525-535.

117. Korenromp, E.L., et al. 2005. Determinants of the impact of sexually transmitted infection treatment on prevention of HIV infection: a synthesis of evidence from the Mwanza, Rakai, and Masaka intervention trials. J. Infect. Dis. 191(Suppl. 1):S168-S178.

118. Watson-Jones, D., et al. 2007. Impact of HSV-2 suppressive therapy on HIV incidence in HSV-2 seropositive women: a randomised controlled trial in Tanzania. Fourth International AIDS Society Confer ence on HIV Pathogenesis. Sydney, New South Wales, Australia. Abstract MOAC104.

119. Celum, C., et al. 2008. HSV-2 suppressive therapy for prevention of HIV acquisition: results of HPTN 039 [abstract]. Fifteenth Conference on Retroviruses and Opportunistic Infections. Boston, Massachusetts, USA. 15:32LB.

120. Celum, C.L., Robinson, N.J., and Cohen, M.S. 2005 Potential effect of HIV type 1 antiretroviral and herpes simplex virus type 2 antiviral therapy on transmission and acquisition of HIV type 1 infection. J. Infect. Dis. 191(Suppl.):S107-S114.

121.Global HIV/AIDS Vaccine Enterprise. 2005. The Global HIV/AIDS Vaccine Enterprise: scientific strategic plan. PLoS Med. 2:e25.

122.Johnston, M.I., and Fauci, A.S. 2007. An HIV vaccine - evolving concepts. N. Engl. J. Med. 356:2073-2081.

123. Montefiori, D., et al. 2007. Antibody-based HIV-1 vaccines: recent developments and future directions. PLoS Med. 4:e348.

124.Flynn, N.M., et al. 2005. Placebo-controlled phase 3 trial of a recombinant glycoprotein 120 vaccine to prevent HIV-1 infection. J. Infect. Dis. 191:654-665.

125. Cohen, J. 2007. Did Merck's failed HIV vaccine cause harm? Science. 318:1048-1049.

126. Roddy, R.E., et al. 1998. A controlled trial of nonoxynol 9 film to reduce male-to-female transmission of sexually transmitted diseases. N. Engl. J. Med. 339:504-510.

127. Van Damme, L., et al. 2002. Effectiveness of COL 1492 , a nonoxynol-9 vaginal gel, on HIV-1 transmission in female sex workers: a randomised controlled trial. Lancet. 360:971-977.

128. Ramjee, G., Govinden, R., Morar, N.S., and Mbewu,
A. 2007. South Africa's experience of the closure of the cellulose sulphate microbicide trial. PLoS Med. 4:e235

129.Feldblum, P.J., et al. 2008. SAVVY Vaginal Gel (C31G) for prevention of HIV infection: a randomized controlled trial in Nigeria. PloS ONE. 3:e474.

130.García-Lerma, J.G., et al. 2008. Prevention of rectal SHIV transmission in macaques by daily or intermittent prophylaxis with emtricitabine and tenofovir. PloS Med. 5:e28.

131.Cohen, M.S., and Kashuba, A. 2008. Antiretroviral therapy for prevention of HIV infection: new clues from an animal model. PLoS Med. 5:e30.

132.Peterson, L., et al. 2007. Tenofovir disoproxil fumarate for prevention of HIV infection in women: a phase 2 , double-blind, randomized, placebo-controlled trial. PLoS Clin. Trials. 2:e27.

133.Grant, R.M., et al. 2005. AIDS: promote HIV chemoprophylaxis research, don't prevent it. Science. 309:2170-2171.

134.Singh, J.A., and Mills, E.J. 2005. The abandoned trials of pre-exposure prophylaxis for HIV: what went wrong? PLoS Med. 2:e234.

135.Cooper, E.R., et al. 2002. Combination antiretroviral strategies for the treatment of pregnant HIV-1-infected women and prevention of perinatal HIV-1 transmission. J. Acquir. Immune Defic. Syndr. 29:484-494.

136.Luo, C., et al. 2007. Global progress in PMTCT and paediatric HIV care and treatment in low- and middle-income countries in 2004-2005. Reprod. Health Matters. 15:179-189.

137. Reynolds, H.W., Janowitz, B., Homan, R., and Johnson, L. 2006. The value of contraception to prevent perinatal HIV transmission. Sex. Transm. Dis. 33:350-356.

138.Guay, L.A., et al. 1999. Intrapartum and neonatal single-dose nevirapine compared with zidovudine for prevention of mother-to-child transmission of HIV-1 in Kampala, Uganda: HIVNET 012 randomised trial. Lancet. 354:795-802.

139.Jackson, J.B., et al. 2001. Identification of K103N resistance mutation in Ugandan women receiving nevirapine to prevent HIV-1 vertical transmission. AIDS. 14:F111-F115.

140.Eshleman, S.H., et al. 2001. Selection and fading of resistance mutations in women and infants receiving nevirapine to prevent HIV-1 vertical transmission (HIVNET 012). AIDS. 15:1951-1957.

141.Jourdain, G., et al. 2004. Intrapartum exposure to nevirapine and subsequent maternal responses to nevirapine-based antiretroviral therapy. N. Engl. J. Med. 351:229-240.

142.McIntyre, J. 2005. Controversies in the use of nevirapine for the prevention of mother-to-child transmission of HIV [abstract]. Conference on Retroviruses and Opportunistic Infections. 12:8.

143. Bunnell, R., et al. 2006. Changes in sexual behavior and risk of HIV transmission after antiretroviral therapy and prevention interventions in rural Uganda. AIDS. 20:85-92.

144.Fraser, C., Hollingsworth, T.D., Chapman, R., de Wolf, F., and Hanage, W.P. 2007. Variation in HIV-1 set-point viral load: epidemiological analysis and an evolutionary hypothesis. Proc. Natl. Acad. Sci. U. S. A. 104:17441-17446.

145. The Associated Press. 31 Jan 2008. Swiss change safe sex message on HIV. USA Today. http://www. usatoday.com/news/world/2008-01-31-switzerland-aids_N.htm.

146. Levy, J.A. 2007. HIV and the pathogenesis of AIDS. 3rd edition. ASM Press. Washington, DC, USA. 588 pp.

147. Salomon, J.A., et al. 2005. Integrating HIV prevention and treatment: from slogans to impact. PloS Med. 2:e16.

148.Stover, J., et al. 2006. The global impact of scaling up HIV/AIDS prevention programs in low- and middle-income countries. Science. 311:1474-1476. 